\title{
A report on Aporcelaimellus sp (Nematoda: Dorylaimidae) from cultivated crops in Rajshahi University Campus
}

\author{
Nuzhat Ara and Mosharrof Hossain \\ Department of Zoology, Rajshahi University, Rajshahi-6205, Bangladesh
}

\begin{abstract}
Aporcelaimellus was identified from different cultivated crops. The genus is within the family Dorylaimidae, and contains robust animals of 0.8 to $3.5 \mathrm{~mm}$ body length. The specimen having the medium-sized body, short odontostyle, unsclerotized vulva, conical, dorsally not concave tail with distinctly separated layers of terminal cuticle. Aporcelaimellus prevalence was the highest in banana ( $80 \%)$ and the lowest was in mulberry $(20 \%)$ during sampling periods. The diagnostic morphology of this nematode was slender vulva lips, thick vagina, and with long anal body with sharply pointed tail.
\end{abstract}

Key word: Nematode, Aporcelaimellus, root nematode, Rajshahi University, Bangladesh.

\section{Introduction}

Plant-parasitic nematodes cause an estimate of annual crop losses approximately $\$ 10$ billion in the USA and $\$ 125$ billion globally (Sasser \& Freckman, 1987). Plant-parasitic nematodes are nearly microscopic, worm-shaped animals virtually invisible to the naked eye when in the soil. They can cause significant plant damage ranging from negligible injury to total destruction of the plant. The severity of plant injury resulting from nematode activity depends on several factors such as the combination of plant and nematode species and prevailing environmental factors including rainfall, soil types, land contour, and culture practices. Although a few nematode species feed on above ground plant parts, such as leaves, stems, flowers, and seeds, the majority of these parasites feed on underground parts of plants, including roots, bulbs, and tubers. Because of this type of feeding activity of nematode, damage to plants cannot always be diagnosed readily.

The genus Aporcelaimellus belongs to the taxonomically rather difficult superfamily Dorylaimoidea (Heyns, 1965). Recently Andrassy (2002) enumerated 86 nominal species of this genus. Less than half of them, 41 species may be treated as independent representatives in Aporcelaimellus, 17 are synonyms, 24 have already been transferred, or should be transferred, to other genera, while 4 species are of uncertain taxonomic value. The genus itself is easily distinguished by morphology. It belongs to the superfamily Dorylaimoidea, and contains robust animals of 0.8 to $3.5 \mathrm{~mm}$ body length. In this paper the prevalence and morphology of Aporcelaimellus collected from the cultivated crops in Rajshahi University Campus has been reported

\section{Material and Methods}

Sampling area and collection: The nematode samples were collected from cultivated crops of a particular area of Rajshahi University Campus. This study area was selected due to repeated cultivation of the same crops cultivars round the year. To accomplish this study, several crop fields were surveyed during the winter season from November, 2006 to March, 2007. Soil and root samples were collected from the study fields where infestation of nematodes were suspected considering visible symptoms described by Ayoub (1980). Samples were collected at random at depth of 5-15 cm surrounding roots and rhizospheres of crop plants. About $500 \mathrm{~g}$ soil along with roots was collected from each place. After collection samples were placed in airtight containers. Polythene bags were used for storing and carrying the samples to the laboratory. Then modified Baermann funnel technique was used to extract nematodes in the laboratory of the Department of Zoology, Rajshahi University according to Robinson and Heald (1989).

Whole mount and microscopic slide: Three or four drops of clear fingernail polish were placed on 
a clean microscope slide in a triangular or rectangular pattern; it was arranged so that the coverslips will span all of them. Using the dropper, a small drop of water containing nematodes was placed in the space defined by the drops. Then carefully pass out the slide over a slow flame six to eight times to relax the nematodes and observed under the dissecting microscope to be sure that the nematodes have stopped moving. Finally nematodes were observed using a compound microscope. The morphology and some internal structures were studied and identified up to genus following taxonomic key (Andrassy, 2002).

\section{Results and Discussion}

Bangladesh lacks available information on the distribution and pathogenicity, as well as the extent of damage, susceptibility and resistance of local cultivars and host range of nematodes. There are four species of nematodes reported in the banana fields in Bangladesh (Hoque \& Hossain 2001). A survey was conducted by Chowdhury et al. (1981) at Joydebpur to identify nematode genera associated with banana. They collected root and soil samples from several banana plantations and identified six nematode genera. Another survey was conducted by Mian (1986) throughout Bangladesh to record the plantparasitic nematodes associated with some important crop species commonly grown in the country where 23 genera of the parasites were recorded. Almost all plant-pathogenic nematodes live a part of their lives in the soil. Many of them live freely in soil, feeding superficially on roots. Here the prevalence of Aporcelaimellus in different crops plant cultivated in Rajshahi University Campus has been reported (Table-1).

Table-1: Prevalence of Aporcelaimellus in the different cultivated crops.

\begin{tabular}{|c|c|c|c|}
\hline Crops & Nematodes & Family & Prevalence (\%) \\
\hline Rice (Oriza sativa) & Aporcelaimellus sp & Dorylaimidae & $20 / 8(40)$ \\
\hline Potato (Solanum tuberosum) & Aporcelaimellus sp & Dorylaimidae & $20 / 12(60)$ \\
\hline Banana (Musa sp) & Aporcelaimellus sp & Dorylaimidae & $20 / 16(80)$ \\
\hline Mulberry (Morus indica) & Aporcelaimellus sp & Dorylaimidae & $20 / 4(20)$ \\
\hline Tomato (Solanum lycopersicum ) & Aporcelaimellus sp & Dorylaimidae & $20 / 12(60)$ \\
\hline
\end{tabular}

The highest number of nematode was found in banana $(80 \%)$ and lowest was in mulberry $(20 \%)$ plants. The soil environment affects the survival and movement of nematodes in the soil. Nematodes occur in greatest abundance in the top 15 to $30 \mathrm{~cm}$ depth of the soil (Agrios 1997). The affected crop plants were severely necrosis in the leaves and the tuber in the present study may be due to the infestation of this nematode (data not shown). A middle-sized, rather robust nematode species with sharply separated head, strong odontostyle, aperture occupying half of the stylet length, an esophagus widening at its middle, comparatively back positioned dorsal nucleus, slender vulva lips, thick vagina with long anal body and sharply pointed tail was studied (Fig. 1).
The characteristic shape of tail, possessing a comparatively long and sharply tipped projection, is unique within the genus. Among the members of Aporcelaimellus, each showing concave contour on the dorsal side of tail. Another distinguishing character is found in the shape of the sclerotized vulval lips which are longer and narrower than is usual in the genus. Meyl (1956) described two genus from Brazil which were later transferred to Aporcelaimellus are similar to this study. Heyns (1965) characterized by strongly separated labial region, double layers of cuticle showing different refraction, short and strong stylet with large aperture, in entire length muscular oesophagus, sclerotized vulva, paired gonads, in each sex similar, short tail, and greatly expanded somatic muscle bands in dorsal side of the hind body. 

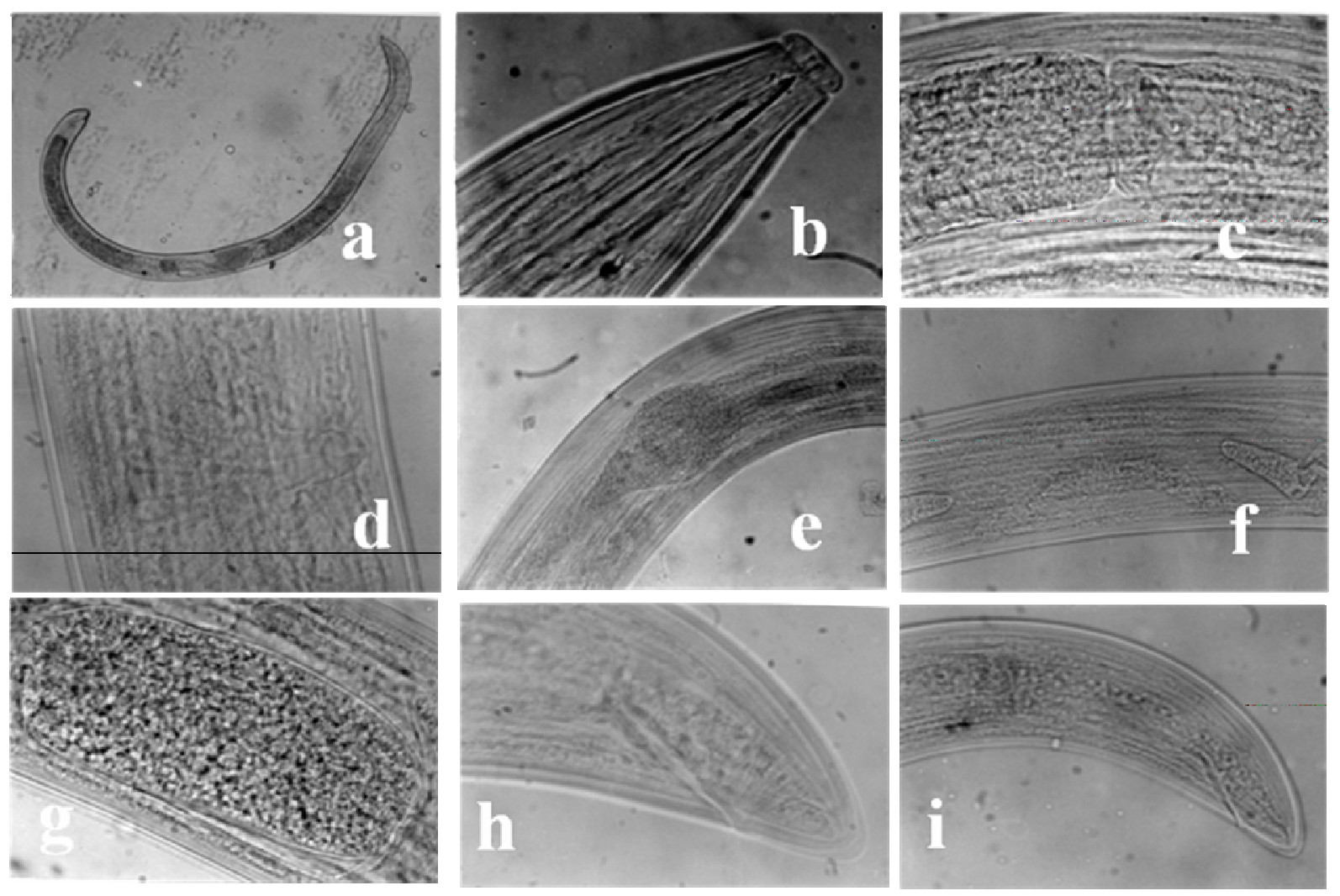

Fig.1. Typical morphology of Aporcelaimellus nematode. [a, whole animal (75x); b, head region showing odontostyle (750x); c, pharyngo-intestinal junction (750x); d, vulva region showing sclerotization (750x); e, reproductive system (300x); f, ovary (750x); g, mature egg $(750 \times)$; h, anus region $(2.5 \times 40) ;$ i, tail region $(2.5 \times 40)]$.

This paper reported a main morphological pattern of the genus is the structure of tail, by which Aporcelaimellus can be easily differentiated from every known species on the other hand. Female gonads paired, opposed, reflexed; orientation of vulva not stated for most species Nematode population density in the roots in this study could be an indicator to determine whether the crops cultivar was resistant to nematode invasion. In addition the $5-15 \mathrm{~cm}$ soil depth of rhizosphere should be emphasized as the important region for chemical control of this pest in the present finding.

\section{Acknowledgements}

The authors are thankful to the Chairman Department of Zoology, Rajshahi University for providing laboratory facilities and two anonymous reviewers for kindly going through the manuscript and offering constructive and helpful suggestions and comments.

\section{References}

Agrios, G.N. 1997. Plant Pathology (4th edition). Academic Press, London, 566pp.

Ali, M.R. 2003. Annual Report. Plant Pathology Division, BARI, Gazipur, Bangladesh.

Andrassy, I. 2002. Free-living nematodes from the Fertö-Hanság National Park, Hungary. In: Mahunka, S. (ed.): The fauna of the Fertö-Hanság National Park, Budapest. pp 21-97.

Ayoub, S.M. 1980. Plant Nematology, an Agricultural Training Aid. NemaAid Publications, Sacramento, CA, $195 \mathrm{pp}$.

Chowdhury, B.C., Geachie, I. M. \& Haque, M.O. 1981. A preliminary investigation on parasitic nematodes associated with banana at Joydebpur. Bangladesh J. Hort. 9: 41-44.

Heyns, J. 1965. On thAe morphology and taxonomy of the Aporcelaimidae, a new family of dorylaimoid nematodes. Entomol. Mem. Dept. Agric. Techn. Serv. S. Africa. pp. 1-51. 
Hoque, M.A. \& Hossain, M.M. 2001. Kola Utpadoner Adhunic Kolakoushal (Modern production technology of banana). Horticulture Research Centre, BARI, Gazipur, Bangladesh.

Hossain, M.H. 2003. Control of nematodes with nematicides and organic amendments. BARI, Gazipur, Bangladesh. Annual Report. Plant Pathology Division. RARS, Jessore, Bangladesh.

Meyl, A. H.1956. Beiträge zur freilebenden Nematodenfauna Brasiliens. I. Acht neue Nematodenarten der Überfamilie Dorylaimoidea. Nematologica 1: 311-325.
Mian, I.H. 1986. Plant-Parasitic Nematode with some Crop species in Bangladesh. Bangladesh J. Plant Pathology 2(1): 7-13.

Robinson, A.F. \& Heald, C.M. 1989. Carbondioxide and temperature gradients in Baermann funnel extraction of Rotylenchus veniformis. J. Nematology, 23: 28-38.

Sasser, J.N. \& Freckman, D.W. 1987. A world perspective on nematology: the role of the society, in Vistas on nematology, ed by Veech JA and Dickson DW, Society of Nematologists, Hyattsville, Maryland, pp 7-14. 